\title{
Assessment of Textural Properties of Kalakand Sold in Parbhani District
}

\author{
Suryakant N. Hakke, Shankar G. Narwade and Sachin V. Gaikwad* \\ Department of Animal Husbandry and Dairy Science, College of Agriculture, \\ Vasantrao Naik Marathwada Krishi Vidyapeeth, Parbhani (M.S.) - 431402 \\ *Corresponding author
}

\begin{tabular}{|l|}
\hline Ke y w o r d s \\
$\begin{array}{l}\text { Kalakand, Buffalo } \\
\text { Milk, Texture }\end{array}$ \\
\hline Article Info \\
\hline $\begin{array}{l}\text { Accepted: } \\
\text { 07 May } 2019 \\
\text { Available Online: } \\
\text { 10 June } 2019\end{array}$ \\
\hline
\end{tabular}

A B S T R A C T

The study was conducted to characterize textural attributes of market and laboratory made Kalakand samples. Three different types of samples of Kalakand procured from the Vicinity of the traditional manufacturing of eleven shops were selected randomly for the study from different region of Parbhani district, the manufacturers manufacturing and selling the product and having good popularity among consumers were selected and the study were replicated four times. Market Kalakand samples were collected and simultaneously one Kalakand sample was prepared in laboratory. For the qualitative preparation of Kalakand, the comparison made between laboratory made plain Kalakand $\left(\mathrm{T}_{1}\right)$ with market plain Kalakand $\left(\mathrm{T}_{2}\right)$, market fig Kalakand $\left(\mathrm{T}_{3}\right)$ and market kashmiri Kalakand $\left(\mathrm{T}_{4}\right)$ with addition of $6 \%$ sugar. Kalakand was evaluated for textural qualities viz., Hardness, cohesiveness, adhesiveness, springiness, gumminess and chewiness. The score for laboratory made Kalakand were $0.266,0.832,0.000,4.285,0.221$ and 0.946 . For plain Kalakand was $0.065,2.547,0.001,3.166,0.165$ and 0.524 . In fig Kalakand was $0.244,0.946,0.001,3.818,0.230$ and 0.881 and Kashmiri Kalakand contained 0.150, $3.506,0.001,3.378,0.525$ and 1.776 per cent, respectively. The rheological properties concerns to hardness are directly related with moisture content of the Kalakand sample, lower content of moisture per cent in Kalakand sample increases the hardness.

\section{Introduction}

Milk is an extremely complex biological fluid with scores of nutrient content contained in fluid characteristics of three physical phases; diluted emulsion, colloidal dispersion and solution. The chemical makeup of milk and its physicochemical behavior provide scientific basis for process of milk and manufacture of products. The increased availability of milk during the flush season coupled with inadequate facilities to keep liquid milk fresh during transit from rural production areas to urban market has led to the conversion of milk into traditional milk products. In addition manufacture of this traditional dairy product help in preservation of milk solids for longer time at room temperature and also creates employment and opportunity. Kalakand is one of the traditional milk products which are made by desiccation of heat with caramelized flavor and granular 
texture prepared from acidified milk. It also accompanies reduction of water activity results in destruction of pathogenic microorganism and inactivation of enzyme activity. The main reaction in preparation is denaturation and coagulation of milk proteins. The color of Kalakand varies from off white to light caramel color. Being a whole milk concentrate, Kalakand is a good source of proteins, minerals, energy giving fat and lactose. It is 4-6 times more nutritious than milk in terms of per unit weight and calorific value (Shalini, 2015). Kalakand has unique importance in market because it is liked by all classes of people. It has specially importance in various celebrations like wedding, inaugural functions, birthday and diwali period. Therefore, the demand for this product is constant throughout the year. Kalakand is indisputable product having economic importance especially in rural part of India as it provides good means for converting surplus milk into value added products. Several varieties of Kalakand i.e. fig Kalakand, mango Kalakand, ash guard Kalakand, sapota Kalakand, kashmiri Kalakand, strawberry Kalakand, plain Kalakand etc. are sold in the market of Maharashtra.

In Parbhani city kashmiri, plain and fig Kalakand are most popular. All the varieties of Kalakand have distinct characteristics and method of manufacture vary from region to region. The base for all these types of Kalakand is however khoa and sugar. In different proportions other ingredients are also incorporated to cater the special need of flavour, body and texture characteristics.

However, so far no serious attention was paid to improve the existing technology and exploit it on large industrial scale. Therefore, this product remained at cottage and small industries in different part of our country resulting into large variation in quality of final product.

\section{Materials and Methods}

\section{Collection of samples}

Preliminary survey was conducted in Parbhani market, to know the different types of Kalakand available in market and their availability throughout the study period. On the basis of survey, the three types of Kalakand purchased from eleven shops and brought to the laboratory and stored at $5^{\circ} \mathrm{C}$ temperature till its use for analytical purpose. Market Kalakand samples were collected and simultaneously one Kalakand sample was prepared in laboratory as a control sample. For control sample, buffalo milk was procured from Buffalo Dairy Farm maintained by department of Animal Husbandry and Dairy Science, Parbhani.

\section{Treatments details}

For the qualitative preparation of Kalakand, the comparison made between laboratory made plain Kalakand $\left(\mathrm{T}_{1}\right)$ with market plain Kalakand $\left(\mathrm{T}_{2}\right)$, market fig Kalakand $\left(\mathrm{T}_{3}\right)$ and market Kashmiri Kalakand $\left(\mathrm{T}_{4}\right)$ with addition of $6 \%$ sugar.

\section{Preparation of laboratory Kalakand}

Laboratory Kalakand $\left(\mathrm{T}_{1}\right)$ was prepared from fresh buffalo milk by adopting the method as suggested by De (2013). Boil the specific quantity of milk in karahi placed over a brisk and non-smoky fire. Stir continuously with a khunti with a circular motion. After 10-15 minutes, add to it the required amount of citric acid as dilute solution in water. This will partially coagulate the milk. At this time vigorous stirring is required to obtain a product of good quality. When a semi-solid stage is reached, add sugar and stir well. Add crushed cardamom if desired. Remove plate and allowed to cool at room temperature. Kalakand is now ready. 


\section{Flow Diagram of Kalakand}

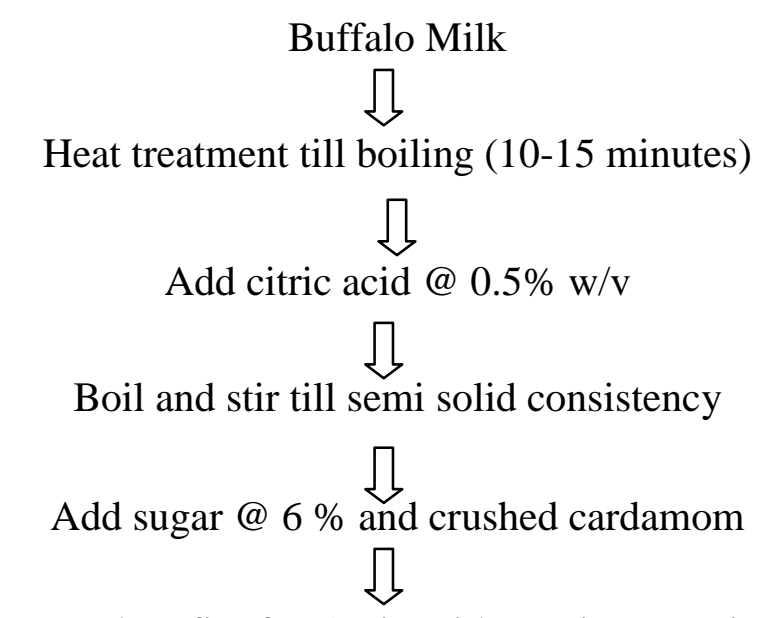

Heat on low fire for $5 \mathrm{~min}$ with continuous stirring

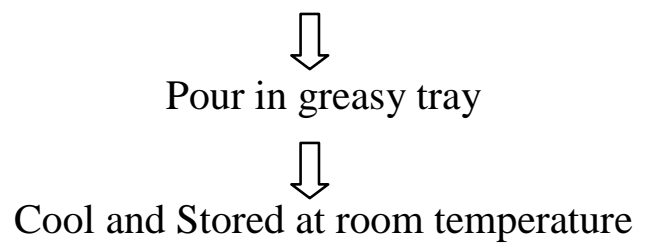

\section{Textural profile analyser}

TPA on samples was performed by using the Texture Analyser TA.XT2 plus of Stable Micro System equipped with $5 \mathrm{~kg}$ load cell to characterize the hardiness, cohesiveness, springiness, adhesiveness, gumminess and chewiness of Kalakand. The samples of Kalakand were cut into $1 \mathrm{~cm}^{3}$ size pieces and their temperature maintained at $25^{\circ} \mathrm{C}$ during the textural analysis. The samples were subjected to mono axial compression of $5 \mathrm{~mm}$ height. The force distance curved was obtained curve was obtained for a two bite compression cycle with the test speed of $1 \mathrm{~mm} / \mathrm{s}$. The pre \& post-test speed were set up at $1.0 \mathrm{~mm} / \mathrm{s} \& 5.0 \mathrm{~mm} / \mathrm{s}$ respectively.

\section{Results and Discussion}

\section{Textural properties samples of Kalakand}

The texture is an important attribute of Kalakand deciding it's acceptability by the consumers. The statistical analysis of various data recorded for textural characteristics of Kalakand samples are presented in Table 1. Analysis of variance of the data pertaining to various textural attributes revealed that hardness, cohesiveness, adhesiveness, springiness, gumminess and chewiness of different Kalakand samples showed significant changes. Detailed findings and relevant discussion is given in following paragraphs.

\section{Hardness}

In textural profile studies, hardness refers to the force required to attain a given deformation (Larmond, 1976). On a two bite force distance curve (Figure 1), it is the highest point of the peak in the first bite compression cycle. The values for hardness of fresh market Kalakand samples varied from $0.065 \mathrm{~g}\left(\mathrm{~T}_{2}\right)$ to $0.244 \mathrm{~g}\left(\mathrm{~T}_{3}\right)$ and laboratory Kalakand sample $0.266 \mathrm{~g}\left(\mathrm{~T}_{1}\right)$. Significant differences $(p<0.05)$ in the hardiness of Kalakand samples were observed. This variation might be due to the variation in 
chemical composition of the Kalakand, amount of sugar added and extent of desiccating and also blending of different levels of fruit pulp in market sample. Hardness of Kalakand depends upon various factors including moisture content and mineral content. Surprisingly, the hardness of laboratory samples was found highest compared to other samples. This may be due to higher khoa content of Kalakand and lower moisture content of sample. These findings are in agreement with Jain et al., (2015) observed variation in textural properties of Kalakand. Hardness of the product is directly related to moisture content, the hardness of Kalakand ranged between $474.57 \pm 0.24^{\text {ba }}$ to $1725.35 \pm 0.69^{\text {ca }}$ (Fig. 1-4).

\section{Cohesiveness}

Cohesiveness refers to the extent to which a material can be deformed before it ruptures (Larmond, 1976). In other words, it refers to how a food product stays together after deformation. It is the ratio of the area under the second peak to that under the first peak and is unit less. The values of Cohesiveness in market Kalakand ranged from $0.946\left(\mathrm{~T}_{2}\right)$ to $3.506\left(\mathrm{~T}_{4}\right)$ and laboratory Kalakand sample had $0.832\left(\mathrm{~T}_{1}\right)$. The cohesiveness was highly significant $(\mathrm{P}<0.05)$ among the all samples presented in Table 1 . These finding are in agreement to results by Arora et al., (2008) reported that the cohesiveness of artificial sweetened Kalakand values were 0.25-0.20.

\section{Adhesiveness}

Adhesiveness is sometimes referred to as stickiness, which is related to how a food adheres to the palate during chewing. The average values of adhesiveness of market and laboratory fresh Kalakand samples are given in the Table 1. The values of adhesiveness in all market Kalakand was 0.001 g.s and laboratory Kalakand sample $\left(\mathrm{T}_{1}\right)$ had lowest and negligible. The adhesiveness was highly significant $(\mathrm{P}<0.05)$ among the all samples. The variation could be due to the difference in raw material used, processing parameter used during manufacturing and chemical composition of Kalakand. This is supported by Jain et al., (2015) reported that the adhesiveness of Kalakand ranged between $0.26 \pm 0.02^{\mathrm{ab}}$ to $0.47 \pm 0.03^{\mathrm{aa}}$ g.s.

\section{Springiness}

Springiness refers to the height that the sample recovers during force relaxation time between first and second bite compression cycle (Patel et al., 2011). The springiness depends on factors such as heat treatment and degree of firmness. The overall mean values of springiness of market and laboratory samples of Kalakand were ranged from 3.166 $\mathrm{mm}\left(\mathrm{T}_{3}\right)$ and $3.818\left(\mathrm{~T}_{2}\right)$ to $4.285 \mathrm{~mm}\left(\mathrm{~T}_{1}\right)$. The mean springiness values differed significantly $(\mathrm{P}<0.05)$. This might be due to the increase in concentration of fruit pulp blend in the market samples of Kalakand. The results agreed with Arora et al., (2008) observed that the springiness of artificially sweetened Kalakand (3.6 to $1.74 \mathrm{~mm}$ ). Kumar et al., (2009) reported that the average springiness of khoa $0.184 \mathrm{~mm}$.

\section{Gumminess}

Larmond (1976) defined gumminess as the energy required to disintegrate a semi-solid food to a state ready for swallowing. It is related to primary parameters of hardness and cohesiveness and is obtained by multiplication of these two parameters. The mean values of gumminess of market Kalakand which varied between $0.165 \mathrm{~g}\left(\mathrm{~T}_{2}\right)$ to $0.525 \mathrm{~g}\left(\mathrm{~T}_{4}\right)$ and laboratory Kalakand had $0.221 \mathrm{~g}\left(\mathrm{~T}_{1}\right)$. The Mean gumminess value differed highly significantly $(\mathrm{P}<0.05)$ among all samples. These finding are in agreement to results by Jain et al., (2015) reported that the 
gumminess of Kalakand ranged between $130.93 \pm 0.84^{\text {aa }}$ to $676.23 \pm 0.73^{\text {dc }}$.

\section{Chewiness}

Chewiness refers to the energy required to masticate food into a state ready for swallowing and is a product of hardness, cohesiveness and springiness (Patel et al., 2011).

The chewiness values differed significantly $(\mathrm{P}<0.05)$ among samples and ranged from
$0.524\left(\mathrm{~T}_{2}\right)$ to 1.776 g.mm $\left(\mathrm{T}_{4}\right)$ in market samples and 0.946 g.mm $\left(\mathrm{T}_{1}\right)$ in laboratory sample.

It might be due to wide variation in chemical composition of the Kalakand samples and variation in the value of hardness, cohesiveness and springiness among samples. These finding are in agreement to results by Kumar et al (2009) reported that the average chewiness of khoa (base material for Kalakand) 1.038.

Table.1 Textural properties of Kalakand sold in Parbhani market

\begin{tabular}{|c|c|c|c|c|c|c|}
\hline $\begin{array}{c}\text { Sample } \\
\text { No. }\end{array}$ & $\begin{array}{c}\text { Hardness } \\
(\mathbf{k g})\end{array}$ & Cohesiveness & $\begin{array}{c}\text { Adhesiveness } \\
(\mathbf{k g})\end{array}$ & $\begin{array}{c}\text { Springiness } \\
(\mathbf{m m})\end{array}$ & Gumminess & $\begin{array}{c}\text { Chewiness } \\
(\mathbf{k g})\end{array}$ \\
\hline $\mathbf{T}_{\mathbf{1}}$ & 0.266 & 0.832 & 0.000 & 4.285 & 0.221 & 0.946 \\
\hline $\mathbf{T}_{\mathbf{2}}$ & 0.065 & 2.547 & 0.001 & 3.166 & 0.165 & 0.524 \\
\hline $\mathbf{T}_{\mathbf{3}}$ & 0.244 & 0.946 & 0.001 & 3.818 & 0.230 & 0.881 \\
\hline $\mathbf{T}_{\mathbf{4}}$ & 0.150 & 3.506 & 0.001 & 3.378 & 0.525 & 1.776 \\
\hline
\end{tabular}

Fig.1 Typical textural profile curve of kalakand sample T1

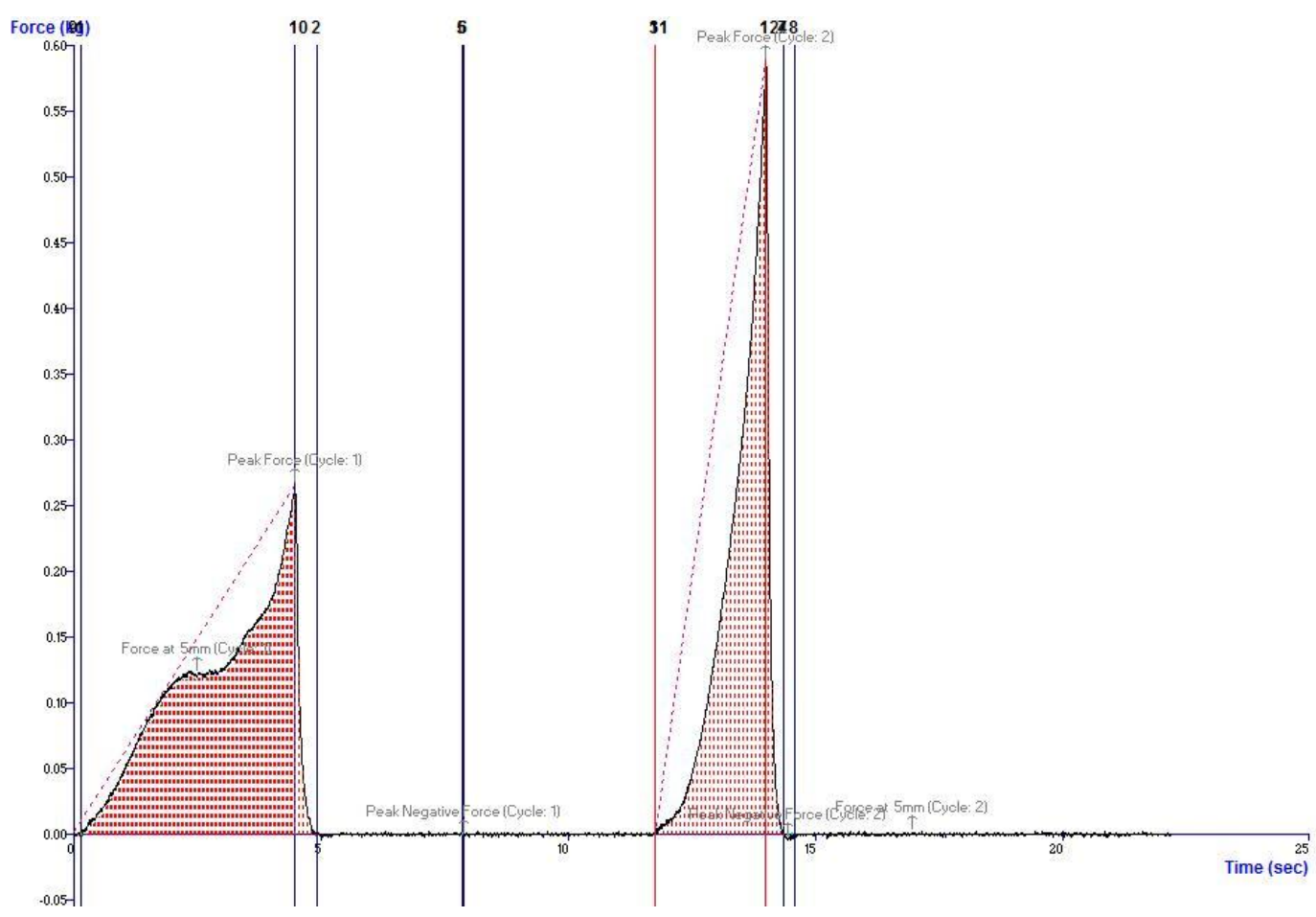


Fig.2 Typical textural profile curve of kalakand sample T2

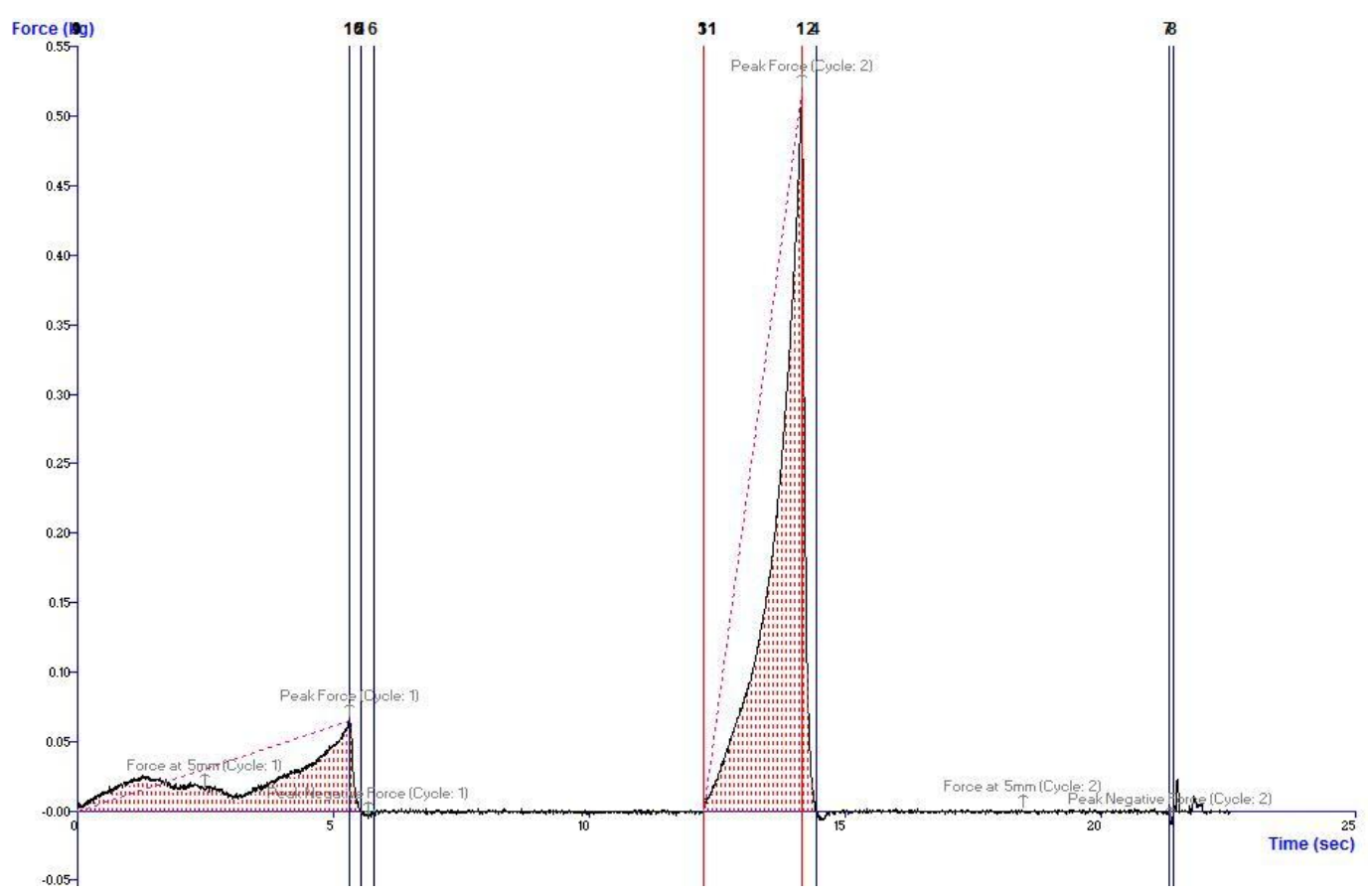

Fig.3 Typical textural profile curve of kalakand Sample T3

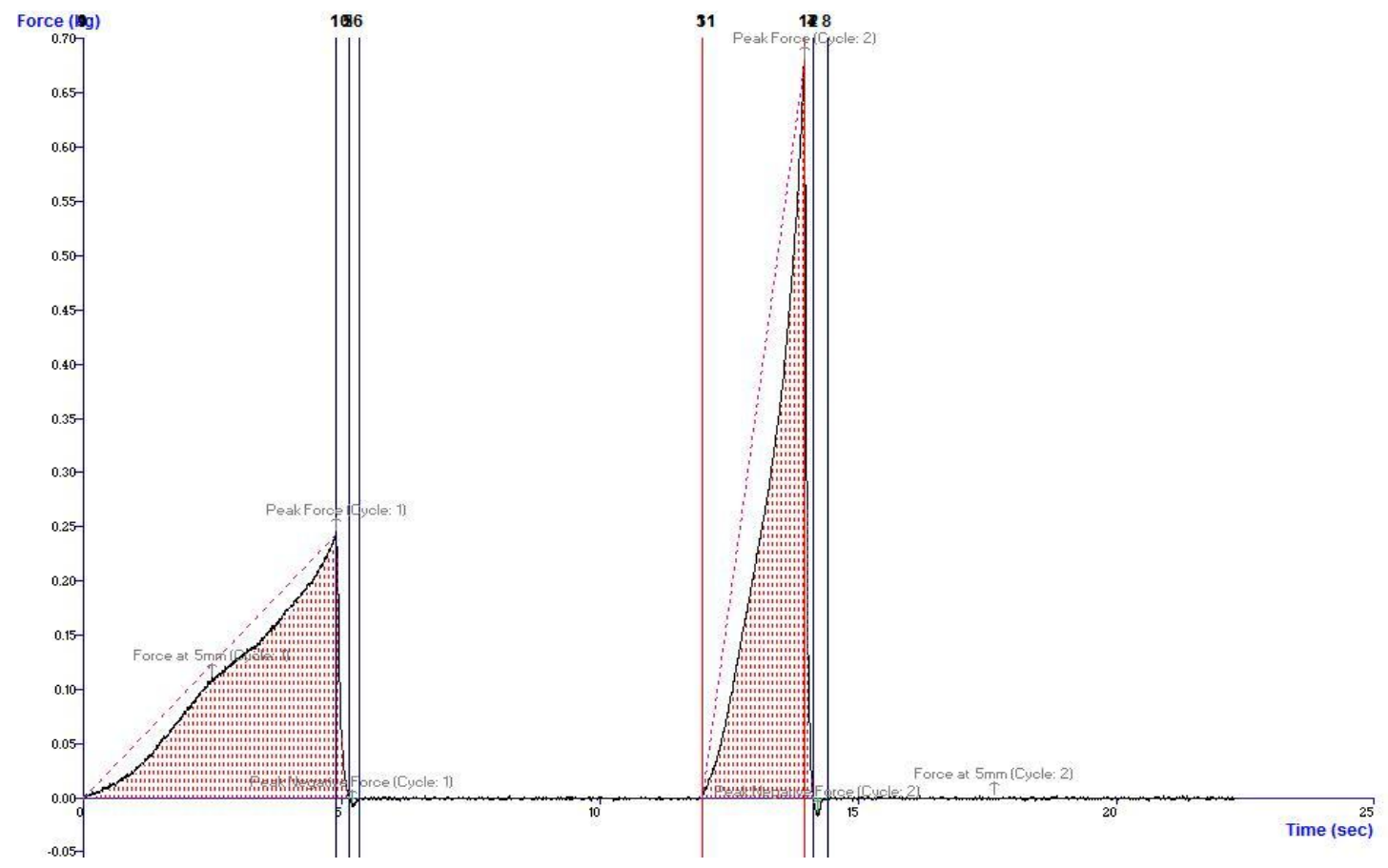


Fig.4 Typical textural profile curve of kalakand sample T4

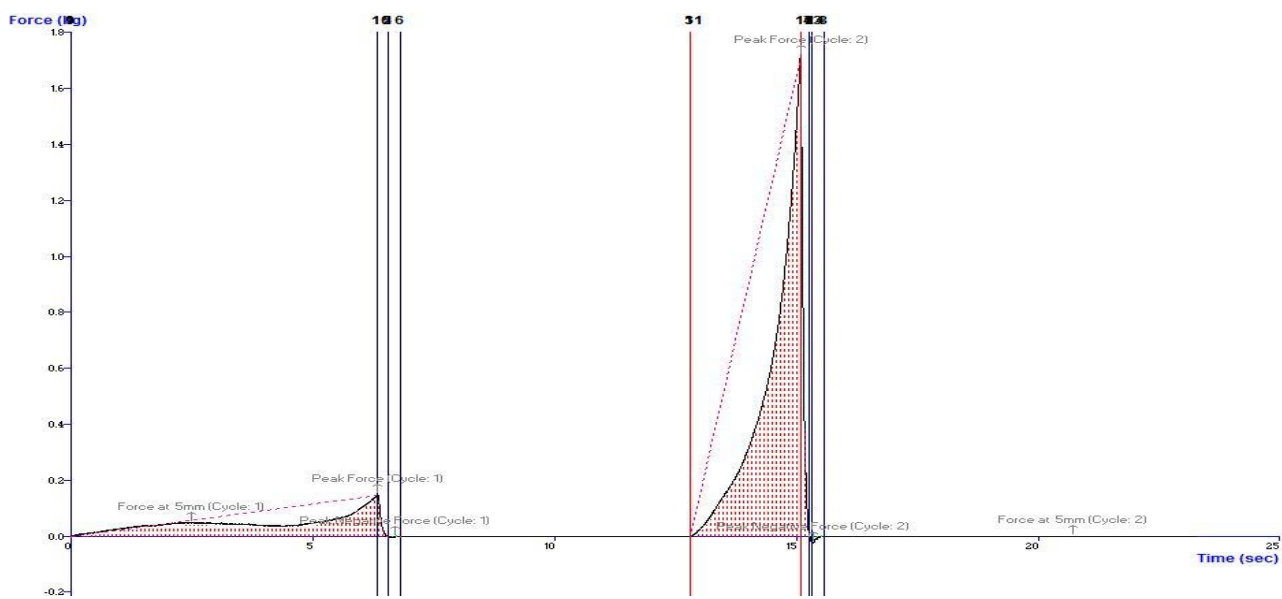

In conclusion, the three different Kalakand samples were collected from eleven different shops in the market of Parbhani district and one laboratory made Kalakand, showed wide variation in their textural profile. This may be due to the variation in their method of preparation and varying levels of pulp, sugar and moisture content. The correlation study indicated that, there is a direct relation between moisture levels and textural variations, which affects also the sensory attributes of the Kalakand samples.

\section{References}

Arora, Gawande, Narendra, Yarrakula, Singh, Sharma, Wadhwa, Tomer, Sharma, 2008. Textural and structural properties of Kalakand made with artificial sweeteners -saccharin, acesulfame-k, sucralose and aspartame. J. Food Sci.Technol. (Mysore). 45 (3): 263-266.

De, S. 1980. Outline of Dairy Technology. Oxford University Press, Bombay. pp: 385-389.

Jain V., Rasane Prasad, Jha alok, Sharma
Nitya,and Gautam, A. 2015. Effect of modified atmospheric packaging on the shelf life of kalakand and its influence on microbial, textural, sensory and physicochemical properties. J. Food Sci. Technol. 52(7): 4090-4101.

Kumar Anil, Agrawala, S.P., Dodeja, A.K. and Pal, D. 2009. Effect of Modification in the third stage scraped surface heat exchanger for continuous Khoa production. Indian Journal of Dairy Science, 60 (3): 175-181.

Lormond, E. 1976. Sensory measurement of food texture. In "Rheology and Texture in Food Quality”. AVI Publishing Co., USA.

Patel, H. A.; Salunke, P. and Thakar, P. N. Comparative appraisal of quality of peda manufactured and sold in selected cities of Gujarat state. International Journal of Dairy Foods, 1 (1): 68-75.

Shalini, Arora P., Chandra, R. and Yadav, G. (2015). Development and quality assessment of papaya kalakand. The Pharma Innovation Journal, 4(5): 8-10.

\section{How to cite this article:}

Suryakant N. Hakke, Shankar G. Narwade and Sachin V. Gaikwad. 2019. Assessment of Textural Properties of Kalakand Sold in Parbhani District. Int.J.Curr.Microbiol.App.Sci. 8(06): 684-690. doi: https://doi.org/10.20546/ijcmas.2019.806.079 